\title{
An Evaluation of the ACRL Statistics Report
}

Mr. Bentz is associate director, State University of Iowa Libraries and chairman, ACRL Statistics Committee.

TN AN EFFORT to appraise the clarity, the 1 adequacy of coverage, and the usefulness of the data which it collects and reports, the ACRL Statistics Committee sent a brief questionnaire to those institutions which submit the annual statistics. Answers to the following questions were requested :

I. Do you use the data reported in C\&RL? In what ways?

2. What facts reported do you find particularly useful?

3. What information is included which in your opinion could be eliminated? or consolidated? or collected less frequently than annually?

4. What information would you like to see added?

5. Are there ambiguities in the questionnaire or in the report? If so, what suggestions for clarification can you make?

6. Are you satisfied with the reporting medium (C\&RL)?

7. Are the data in c\&RL difficult to use? Suggestions for improvement?

8. Do you feel that the ACRL statistics could replace the Princeton (ARL) statistics?

9. Do you favor omitting from the published tables those institutions which do not report salary data?

ro. Should the Committee attempt to secure additional special information from time to time? These data might then be used as bases for investigation into special problems. Any suggestions?

II. Other. (Please feel free to comment on or to criticize any aspect of the Committee's work.)

Replies were received from 127 librarians representing the following groups included in the published tables of COLLEGE AND RESEARCH LIBRARIES, January I954. Fortynine out of 70 Group I libraries responded. Twenty-nine Group II out of a possible 67, 24 Group III out of 69 , and 14 Teachers Colleges out of 57 institutions sent in replies. Eleven replies were received from libraries not included in last year's published tables. Apparently the larger libraries are more interested in this problem of collecting statistics since 70 per cent replied. Although more librarians might have responded, an analysis of the data received may indicate a trend in the thinking of librarians generally.

TABLE I

Use Made of Statistics

\begin{tabular}{c|c|c|c|c|c|c}
\hline Use & I & II & III & T.C. & Unpublished & Total \\
\hline Budget Planning & 22 & I3 & 5 & 6 & 7 & 53 \\
Comparative Purposes & I7 & I5 & I6 & 7 & 4 & 59 \\
\hline Total & 39 & 28 & 21 & I3 & I I & I I2* \\
\hline
\end{tabular}

" I3 others reported "yes" and remaining 2 libraries indicated no use made of statistics. 
TABLE II

Most Useful Published Data

\begin{tabular}{l|c|c|c|c|c|c}
\hline \hline \multicolumn{1}{c|}{ Data } & I & II & III & T.C. & Unpublished & Total \\
\hline Salaries & 27 & I2 & 6 & 2 & 6 & 53 \\
Operating Expenditures & I9 & 7 & 4 & 3 & 4 & 37 \\
Size of Collection & I0 & 7 & 3 & 2 & 4 & 26 \\
Everything & I0 & 7 & 5 & 2 & I & 25 \\
Number of Staff & 5 & 9 & I & 4 & 2 & 2 I \\
Volumes Added & 8 & 5 & 3 & 2 & I & I9 \\
Ratio Library to Institu- & & 6 & 4 & 4 & - & I8 \\
tional Expenditures & 4 & 4 & 4 & 2 & 3 & I7 \\
Budget & 4 & 4 & & & & \\
\hline
\end{tabular}

TABLE III

Additional Information Desired

\begin{tabular}{l|c||l|c}
\hline \hline \multicolumn{1}{c|}{ Information } & Total & \multicolumn{1}{|c|}{ Information } & Total \\
\cline { 2 - 4 } None & 53 & Faculty Status & 3 \\
Circulation Statistics & 24 & Sick Leave & 3 \\
Hours of Service & I5 & Inter-library Loans & 2 \\
Vacations & I0 & Number on Library Staff by Depart- & \\
Audio-visual Budgets & 8 & ment & 2 \\
Data from more Libraries & 5 & Number of Branch Libraries & 2 \\
Pay for Student Help & 5 & & \\
\hline
\end{tabular}

TABLE IV

Satisfied with Reporting Medium

\begin{tabular}{c|c|c|c|c|c|c}
\hline \hline Response & I & II & III & T.C. & Unpublished & Total \\
\hline Yes & 42 & 24 & I9 & I3 & II & I09 \\
No Comment & 7 & 5 & 5 & I & - & 18 \\
\hline
\end{tabular}

General Comments and Usefulness of Above Data to the ACRL

\section{Statistics Committee}

Your ACRL Statistics Committee had hoped that the information received would help in revising the Reporting Form for 1953/54, however, little change seemed to be desired by the membership. A tally of the questionnaires indicated that 79 libraries, or $62 \%$ of those reporting, suggest that no information should be eliminated, consolidated, or collected less frequently than annually. Table III shows that 53 institutions reported "none" to the question, "What information would you like to see added ?" Seventy-one libraries reported there were no ambiguities. One hundred and nine institutions were satisfied with COLLEGE AND RESEARCH LIBRARIES as the reporting medium (Table IV) 87 indicated the data were not difficult to use (Table V); 38 said the Committee should not attempt to secure any special information from time to time, and the 24 institutions that replied in the affirmative had no suggestions to make.

The Committee had no motive in asking the question regarding the Princeton (ARL) statistics other than possibly considering the elimination of duplicate effort 
TABLE V

Are the Data in C\&RL. Difficult to Use?

\begin{tabular}{l|c|c|c|c|c|c}
\hline \multicolumn{1}{c|}{ Response } & I & II & III & T.C. & Unpublished & Total \\
\cline { 1 - 5 } No & 24 & 24 & I9 & II & 9 & 87 \\
Clearer Layout of Printed & I5 & I & - & - & 2 & I8 \\
Did Not Answer & I0 & 4 & 5 & 3 & - & 22 \\
\hline
\end{tabular}

TABLE VI

Should ACRL Statistics Replace Princeton (ARL) Statistics?

\begin{tabular}{l|c|c|c|c|c|c}
\hline \multicolumn{1}{c|}{ Response } & I & II & III & T.C. & Unpublished & Total \\
\hline Yes & 27 & I8 & 8 & 8 & 7 & 68 \\
No & I6 & I & 4 & -6 & I & 22 \\
No Opinion & 6 & I0 & I2 & 6 & 3 & 37 \\
\hline
\end{tabular}

TABLE VII

Should Institutions Withholding Salary Data Be Omitted from Published Tables?

\begin{tabular}{l|r|r|r|r|r|c}
\hline \multicolumn{1}{c|}{ Response } & I & II & III & T.C. & Unpublished & Total \\
\hline No & 38 & 24 & I5 & 9 & 9 & 95 \\
Yes & 7 & 4 & 4 & 3 & 2 & 20 \\
Did Not Answer & 4 & I & 5 & 2 & - & I2 \\
\hline
\end{tabular}

and information on the part of many libraries. Sixty-eight libraries, or $54 \%$ of those replying, felt that the ACRL report could replace the Princeton statistics (Table VI). It is true that the same information is included and the data are made available at approximately the same time. Further, the same institutions could report to ACRL. The problem resulting from lack of continuity need not exist if the same institutions would submit reports regularly and would report fully.

\section{INADEQUacies in the Statistics of Recent Years}

A careful study of the different categories of information supplied reveals many inequalities. Since most librarians do use the data for budget planning, a more sound basis for valid comparison is necessary. Look at a few of the many inconsistencies in reporting:
I. Number on Faculty. What constitutes a faculty member? Does one include teaching assistants and part-time instructors? It is possible to equate them to full-time on a uniform basis?

2. Student Enrollment. When is a student a graduate student? How are students in professional schools reported when they already have an undergraduate degree?

3. Book Stock and Volumes Added. There is a difference in the counting of holdings. Some institutions use a bibliographical method of counting; others, a physical volume count; and some, a modified form of both. This is an age old problem. ${ }^{1}$ Some libraries include all state and federal documents, others do not include any, and some report only those that are bound and fully cataloged.

4. Number of Periodicals. Many institutions include all serials. Serials record

1 Downs, Robert B., "Uniform Statistics for Library Holdings." Library Quarterly, I6:63-69, January, I946; Lyle, Guy R., "Counting Library Holdings." college AND RESEARCH LIBRARIES, I I :69-72, January, I950. 
files are not broken down according to the definition of a periodical. The serials figure alone is meaningless since some libraries catalog monographic literature as separate titles and hence count them as physical volumes.

5. Expenditures for Periodicals. This should not include cost of serials and yet many files do not show the cost of periodicals separately.

6. Per Student Operating Expenditures and Ratio of Library Expenditures to Total Institutional Expenditures. These are not valid figures because of the many enrollment categories and differences in the programs of institutions. Does it take fewer or more library materials for special day and night students? Doesn't it cost more to run a library if an institution has a predominantly strong graduate program? Isn't a highly departmentalized system more expensive than one that is centralized?

7. Salary Data. Too few institutions report full information. The data now received are not comparable because of divergent personnel classification systems and differences in the interpretation of who is a professional librarian. Many professional positions on some library staffs are filled by non-academic positions on others.

8. Lack in the continuity of reporting full information by the same institutions.

\section{Changes Made in the 1953/54 REPORTING FORM}

As a result of the Committee's deliberations in Minneapolis, some changes were made on this year's reporting form based on the majority opinion expressed in the questionnaire. The possibility of reporting all salary information by the "range method" rather than by position was considered, but since the present arrangement has been used for the past twenty years and since the librarians responding to the questionnaires found the salary data to be the most useful (see Table II above), no change was recommended.
The number on the faculty has been eliminated because few librarians computed the figure in the same manner. Also, this type of information is available through other sources.

The Committee asked that the student enrollment figure correspond to the one reported to the U.S. Office of Education and published in Fall Enrollment in Higher Educational Institutions. Further, it was requested that only students enrolled in the Graduate College be counted as graduate students.

Expenditures for books and periodicals were combined under one heading. This figure previously was not given separately by many libraries and frequently the expenditures for periodicals included all serials.

The median salary figure by position was eliminated and the number in each position was added. Many librarians felt this median figure was not too useful and that it required too much time to compute. Division heads were placed with department heads unless the former were also associate or assistant chief librarians.

Length of work week both by hours and days was requested only as a sample of the kind of special information that might be collected from time to time.

\section{The Committee's Hope for The Future}

A great amount of time, effort, and expense is involved in publishing the ACRL statistics. The Committee would like very much to give the membership what it wants, but in so doing, cooperation is necessary. There is need for more careful and continuous reporting by the same institutions year after year, and for the submission of all data requested. An attempt should be made by all libraries to report salary information

(Continued on page 92) 
and reference librarians (and this doesn't mean just administrators!) will, we hope, agree to be on hand at stated times to meet other members and discuss their problems or just chat. Those who come to conference can determine before they come that they will have an opportunity to discuss the care of rare books with an authority on, say, Monday morning, or allocation of the book budget with someone else on, possibly, Thursday afternoon. In addition to librarians there should be present for consultation the secondhand bookseller, the binder, and perhaps others of the book world who share interests with us and are not heavily represented in the exhibition area. We hope to make this meeting area attractive and comfortable, a place where our members, both old and young, will relax and fraternize.

Through this consultation service and through our discussion groups we hope to be able to help college and reference librarians with most of their important practical problems. It is expected that the ACRL member can justify to his administration the expense money to attend conference by stating the problems he faces and with which he will be assisted at conference. If members will send to headquarters those problems which are of great personal concern, your secretary will see that these are covered in the discussion groups. No one should expect to get at conference neat little answers to all the problems of "back home." But he should get oriented in the right directions to find his own answers. In other words, the workshop is similar to the school which seeks to motivate the student, catch his interest, guide his thinking, etc. so that he is enabled to find his own answers, and so that he continues his search and solution long years later. It should develop selfperception, a sense for experimentation, new horizons, and sketch out some new techniques. -Arthur T. Hamlin, Executive Secretary.

\section{An Evaluation of the ACRL Statistics Report}

\section{(Continued from page 57)}

fully. One ironical part of the data assembled above is that although the majority of librarians reported the salary data to be the most useful (Table II), 95, or approximately $75 \%$, did not favor omitting those institutions from the published tables which do not submit this important information (Table VII). Few libraries are restricted by university statutes from reporting staff salaries, and yet an increasing number fail to submit these statistics. While reporting salaries in the lower brackets, many chief librarians withhold the top administrative ones because publication may reveal an individual's salary. An argument is that any figure reported may not be representative of one's total earnings. What an individual earns by extra teaching and consultant work is his personal affair, but the fixed salary an institution pays its librarian has great significance for the profession! Only when these figures are reported do the statistics become an important tool for comparative purposes.

In this article, an attempt has been made to evaluate the ACRL statistics and to point out some of the problems facing the Committee. In making a critical analysis of the published data, one could pursue further many of the points raised in this article as well as mention others, but perhaps what has been included will indicate the need for serious thinking among librarians. The Committee is endeavoring to give you useful and accurate information, and your continued cooperation will enable it to function more effectively. 